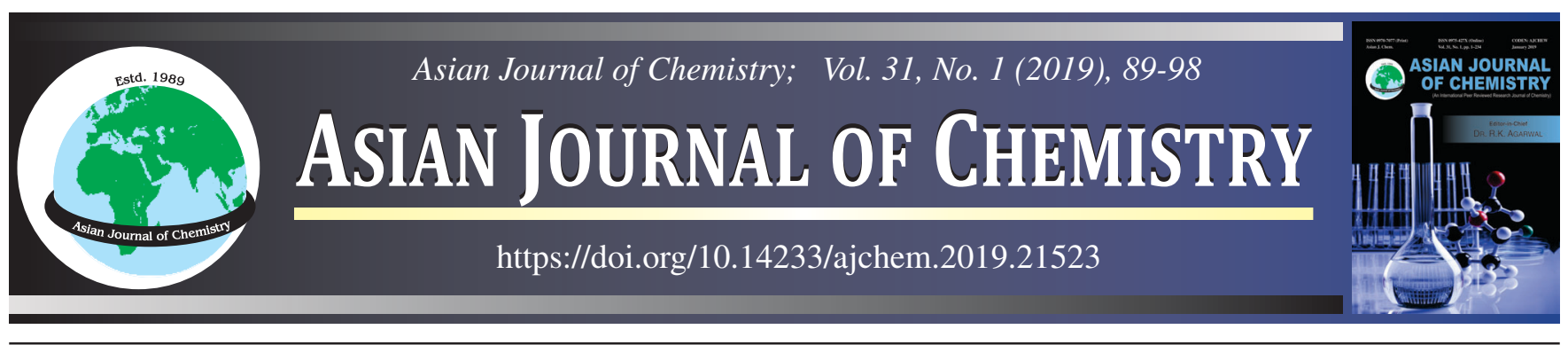

\title{
Aqueous Solubility Enhancement and Desorption of Sudan III Dye from Contaminated Soil Using Plant Based Natural Surfactant
}

\section{M.C. Somasekhara Reddy ${ }^{1,2, *}$, K. Sridevi ${ }^{1,3}$, S.M. Sarvar Jahan ${ }^{1}$ and G.V. Subba Reddy ${ }^{3}$}

${ }^{1}$ Department of Basic Sciences, G.P.R. Engineering College (Autonomous), Kurnool-518007, India

${ }^{2}$ Section of Chemistry, Department of Education in Science and Mathematics (DESM), Regional Institute of Education (RIE), Mysore-570006, India

${ }^{3}$ Department of Chemistry, Jawaharlal Nehru Technological University Engineering College, Pulivendula-516390, India

*Corresponding author: E-mail: mcsr.gprec@gmail.com; som16@rediffmail.com

Received: 16 June 2018;

Accepted: 16 August 2018;

Published online: 30 November 2018;

AJC-19164

\begin{abstract}
A plant based natural surfactant was extracted from fruit pericarp of Sapindus mukorossi, commonly known as soap nuts. The natural surfactant was used for the treatment of the soils which were contaminated with hydrophobic organic compounds like organic dye, Sudan III and the dye was removed/recovered from the soils. This biosurfactant has great advantages when used in environmental remediation as it is environment friendly in nature. Using a simple water extraction of fruit pericarp powder, the natural surfactant was prepared. The natural surfactant solutions were employed to enhance the aqueous solubility of hydrophobic organic compounds like organic dye, Sudan III and to desorb organic dye Sudan III from contaminated soils in batch experiments. The performance of natural surfactant for the removal of Sudan III was compared with that of commercial surfactants like sodium dodecyl sulphate (SDS) (anionic surfactant), cetyltrimethylammonium bromide (CTAB) (cationic surfactant) and Triton X-100 (TX 100) (non-ionic surfactant). The aqueous solubility enhancement of Sudan III dye in presence of $0.04 \mathrm{M}$ of NaCl was increased in case of non-ionic surfactants like natural surfactant (NS) and TX 100. The solubility of Sudan III dye in presence of $0.04 \mathrm{M}$ of $\mathrm{NaCl}$ was decreased in case of ionic surfactants like SDS and CTAB. The desorption behaviour observed for natural surfactant was similar to TX 100 solutions. The natural surfactant solution performance was more or less similar to synthetic surfactants and the removal capacity of surfactant was given in increasing order as TX $100>$ NS $>$ SDS $>$ CTAB
\end{abstract}

| Keywords: Plant-based surfactant, Natural surfactant, Soil contamination, Dyes, Sudan III, Desorption, Solubility.

ᄂ - - - - - - - - - - - - - - - - - - - - - - - - - - - -

\section{INTRODUCTION}

Polycyclic aromatic hydrocarbon (PAH) compounds are non-polar hydrophobic organic compounds comprising two or more fused benzene rings, with meagre aqueous solubility [1]. These compounds may be released to the environment through the disposal of coal tar and other coal processing wastes, petroleum sludges, asphalt, creosote and other wood preservative wastes like pentachloro phenol, chemical wastes and soot [2]. There were many wood preservative sites contaminated with pentachloro phenol in Canada. The major sources of other organic contaminants like PAHs are in coal storage sites, coking sites and tar ponds. In addition, organic contaminants are also generated from the industrial wastes like in the manufacturing process of halogenated phenols and other halogenated compounds, pesticides or pesticide derivatives, halogenated benzene under alkaline conditions. Other sources were industrial leaks from oil and chemical storage tanks or/ and spills, improper application of pesticides, careless disposal of cleaners, oils and antifreeze, improper disposal of household wastes and landfills and garbage dumps. Maximum contaminants limits and health effects of certain organic compounds are arranged in Table-1 for understanding the importance of remediation of soil.

Polycyclic aromatic hydrocarbons are highly hydrophobic and tend to partition onto hydrophobic adsorbents. As a consequence, they can be expected to sorb to soil constituents or to be present as a separate hydrocarbon phase on the subsurface. To site an example coal will form a dense non-aqueous phase liquid (DNAPL) in highly contaminated soils [3]. The

This is an open access journal, and articles are distributed under the terms of the Creative Commons Attribution-NonCommercial 4.0 International (CC BY-NC 4.0) License, which allows others to copy and redistribute the material in any medium or format, remix, transform, and build upon the material, as long as appropriate credit is given and the new creations are licensed under the identical terms. 


\begin{tabular}{|c|c|c|c|}
\hline \multicolumn{4}{|c|}{$\begin{array}{c}\text { TABLE-1 } \\
\text { MAXIMUM CONTAMINANT LIMITS (MCL) AND HEALTH }\end{array}$} \\
\hline Contaminant & $\mathrm{MCL}(\mathrm{mg} / \mathrm{L})$ & Health effect & Source \\
\hline PAHs & 0.0002 & Reproductive difficulties; increased risk of cancer & $\begin{array}{l}\text { Leaching from lining of water storage tanks and } \\
\text { distribution lines, coal storage }\end{array}$ \\
\hline Benzene & 0.0050 & $\begin{array}{l}\text { Anemia; decrease in blood platelets; increased risk } \\
\text { of cancer }\end{array}$ & $\begin{array}{l}\text { Discharge from factories; leaching from gas } \\
\text { storage tanks and land fills }\end{array}$ \\
\hline Alachor & 0.0020 & $\begin{array}{l}\text { Eye, liver, kidney or spleen problems; anemia; } \\
\text { increased risk of cancer }\end{array}$ & Runoff from herbicide used on row crops \\
\hline Carbon tetrachloride & 0.0050 & Liver problems; increased risk of cancer & Discharge from chemical plants \\
\hline Carbofuran & 0.0400 & $\begin{array}{l}\text { Problems with blood, nervous system or } \\
\text { reproductive system }\end{array}$ & Leaching of soil fumigant used on rice and alfalfa \\
\hline $\begin{array}{l}\text { 1,2-Dibromo-3- } \\
\text { chloropropane }\end{array}$ & 0.0002 & Reproductive difficulties; increased risk of cancer & $\begin{array}{l}\text { Runoff/leaching from soil fumigant used on soya } \\
\text { beans, cotton, pineapple and orchards }\end{array}$ \\
\hline
\end{tabular}

contamination of soils by these aqueous insoluble organic compounds is a widespread environmental problem because of their adverse impact on human health due to slow degradation and less water insolubility. Subsurface contamination by the organic compounds is a complex process and difficult to treat due to many reasons like the tendency of adsorption of contaminants onto the soil matrix, low water solubility and limited rate of mass transfer for biodegradation and so on.

Conventional pump-and-treat remediation techniques, which rely on the desorption or dissolution of contaminants into the aqueous phase, were unsuccessful in completely removing PAH and other hydrophobic chemicals from contaminated soils [4]. Moreover, this method required long times [5] to significantly reduce the mass of contaminants in the subsurface.

This kind of problem of soil pollution has gained universal recognition in recent years. Issue of cleaning contaminated soil assumes grave significance. The addition of surfactants is suggested [6-10] so as to improve remediation of contaminated sites by assisting the solubilization of sorbed compounds or DNAPL or any other insoluble organic compounds like PCBs, chlorinated phenols, accidental spills, organic solvents, leaks of organic hydrocarbons like petroleum hydrocarbons, dioxins, furans etc. [11-13]. These hydrophobic organic compounds are classified as carcinogenic or mutagenic.

Use of surfactant solutions for soil washing has two advantages, (i) surfactant molecules tend to concentrate at the organic/aqueous interfaces and lower the interfacial tension considerably and (ii) surfactant molecules also form aggregates known as micelles at concentrations beyond the critical micelle concentration (CMC) that can solubilize hydrophobic organic compounds (HOCs). For the remediation of subsurface soils contaminated with complex wastes at hazardous waste sites [14], mostly synthetic surfactants are currently being tested. Although many commercial surfactants have shown good potential in terms of recovery of contaminants from soil [10], their fate in the subsurface is still unknown. Synthetic surfactants cause environmental and toxicological issues as they release carcinogenic toxins in the environment [15].

An alternative to commercial or synthetic surfactant, should have added advantages like less toxic, more biodegradable, higher foaming capacity, highly selective and specifically active extreme temperatures, $\mathrm{pH}$ and salinity [16]. The natural surfactants derived from plants, specially belonging to the genus Sapindaceae has above advantages. Sapindaceae plants produce saponaceous substances called natural surfactants, which lather or foam in water. Sapindus mukorossi, a tree generally grown in tropical regions of Asia. The dry fruits are generally called as soap nuts due to its excellent detergent property. It is used as a substitute for soap and as a folk medicine in the villages. These are known as Reetha in Hindi and Kunkudu kaya in Telugu. Medicinal properties are attributed to these fruits, which reveal anti-inflammatory [17] and antimicrobial activities [18]. Traditionally it is used as Ayurvedic medical treatment of excessive salivation, epilepsy, psoriasis and for removing freckles [19]. It is also used as insecticide and fungicide separately or mixed with some other additives. It is not causing any toxic effect on skin and eyes of human beings [20].

Recently, the natural surfactant obtained from pericarp of Sapindus mukorossi was used for understanding the interactions with congo red [21], neutral red [22], methylene blue and eosin yellow [23]. Further, this is used to understand its ability to solubilize vegetable oils [24], for the preparation of nanoparticles $[15,25]$, for understanding surface and foam characteristics of saponins [26], synthesis of monodisperse lattices [27], surfactant enhanced oil recovery [28], solubilization of naphthalene [29], removal of phenolic compounds [30] and for solubilization of foreign materials present in muga silk [31]. Seed of soapnuts produce non-edible oil that can be used as biodiesel [32].

This natural surfactant was successfully used in the remediation of contaminated soils for the removal of naphthalene and hexachlorobenzene by enhancing aqueous solubility [20], for the removal of phenanthrene [9], for bioremediation of polycyclic aromatic hydrocarbons [7], for aqueous solubility enhancement and desorption of hydrophobic organic compounds [33], used for the preparation of colloidal gas aphron suspensions for soil flushing [34], these colloidal gas aphrons used for the recovery of pulp fibres from paper machine backwater in a floatation column [35], for simultaneous removal of cadmium and phenanthrene [36,37], arsenic from contaminated soil [38], zinc from contaminated soil [37,39], as well as $\mathrm{Pb}, \mathrm{Cu}$ and PCB from contaminated soil [40].

The applications of natural surfactant are not yetfully explored. In scientific work it has a limited application therefore, interest led researchers to harness its potential applications to solubilize the insoluble organic dye, Sudan III and used this in the treatment of contaminated soils. In the present study, non-toxic, biodegradable, renewable, plant origin, high 
foaming capacity natural surfactant was introduced to understand the aqueous solubility enhancement of insoluble organic dye, Sudan III and to understand the soil remediation of natural surfactant through batch desorption. The performance of natural surfactant in the aqueous solubility enhancement of insoluble organic dye, Sudan III and in treatment of contaminated soil was compared with those commercial surfactants like CTAB, SDS and Triton X-100.

\section{EXPERIMENTAL}

Water insoluble dye, Sudan III, cetyltrimethylammonium bromide (CTAB), sodium dodecyl sulphate (SDS), Triton X100 , sodium hydroxide and distilled water were used in these investigations. All the chemicals were analytical grade.

Sudan III was also labeled as Sudan Red B. This water insoluble Sudan III was used to understand the solubilization properties of natural surfactant and it was treated as a model pollutant (hydrophobic organic compound). Sudan III was used for contaminating the soil. Sudan III was procured from M/s Fluca Chemicals, India. Its IUPAC name was 1-(4-(phenyldiazenyl)phenyl) azonaphthalen-2-ol $\left(\mathrm{C}_{22} \mathrm{H}_{16} \mathrm{~N}_{4} \mathrm{O}\right)$ and its gram molecular weight was $352.4 \mathrm{~g} \mathrm{~mol}^{-1}$.

The doubled distilled water was used for the preparation of solutions wherever required unless otherwise it was specified.

Sodium chloride was procured from M/s Qualigens Fine Chemicals, India. $2 \mathrm{M}$ stock solution of sodium chloride was prepared by using distilled water. It was diluted by using distilled water depending on the requirement.

Cetyltrimethylammonium bromide (CTAB) was procured from M/s Fluka Chemicals, India. Its chemical formula was $\mathrm{C}_{16} \mathrm{H}_{33}\left(\mathrm{CH}_{3}\right)_{3} \mathrm{NBr} / \mathrm{C}_{16} \mathrm{H}_{33}\left(\mathrm{CH}_{2} \mathrm{CH}_{3}\right)_{3} \mathrm{NBr}$ and gram molecular weight was $364.45 / 406.53 \mathrm{~g} \mathrm{~mol}^{-1} .10 \mathrm{mM}$ stock solution of CTAB was prepared [10]. It was diluted by using distilled water depending on the requirement.

Sodium dodecyl sulphate (SDS) was procured M/s Fluka Chemicals, India. Its chemical formula was $\mathrm{CH}_{3}\left(\mathrm{CH}_{2}\right)_{11} \mathrm{OSO}_{3} \mathrm{Na}$ and its gram molecular weight was $288.38 \mathrm{~g} \mathrm{~mol}^{-1} .25 \mathrm{mM}$ stock solution of SDS was prepared. It was diluted by using distilled water depending on the requirement [10].

p-tertiary-Octylphenoxy polyethyl alcohol (Triton X-100) was procured from $\mathrm{M} / \mathrm{s}$ Fluka Chemicals, India. Its chemical formula was $\mathrm{C}_{8} \mathrm{H}_{17} \mathrm{C}_{6} \mathrm{H}_{4}\left(\mathrm{OCH}_{2} \mathrm{CH}_{2}\right)_{9} \cdot 5 \mathrm{OH}$ and its gram molecular weight was $628 \mathrm{~g} \mathrm{~mol}^{-1} .20 .04 \mathrm{mM}$ stock solution of TX 100 was prepared. It was diluted by using distilled water depending on the requirement [10].

Soap nut pericarp powder: $3 \mathrm{~kg}$ of Soap nut fruits (Scientific Name: Sapindus mukorossi) were procured from the local market of Kurnool, Andhra Pradesh (State) India at the cost of Rs. 30/- per kg. These soap nut fruits were golden brown in colour and globular in shape with a diameter between 1 and $3 \mathrm{~cm}$. After removing the seed, the outer pericarps were dried in an oven at $50{ }^{\circ} \mathrm{C}$ for about 2 days. The dried pericarps were ground into powder by using domestic grinder and the powder was sieved through U.S. Standard No. 20 sieve (840 $\mu \mathrm{m})$. The soapnut pericarp powder was stored in Pearle pet (Plastic) bottles for using in experiments.

Chosen soil sample: The soil sample was collected at a village, Nagalapuram, which was about $10 \mathrm{~km}$ away to the
Kurnool city. The soil sample was brought to the college by a private party for the analysis purpose (for consultancy work). This soil was used for experimental purpose. Under the supervision of an expert, a composite soil sample was collected from the first layer aquifer. The soil was dried in an oven overnight at $105{ }^{\circ} \mathrm{C}$. The sample was crushed and passed through the $600 \mathrm{~mm}$ sieve. This sample was taken for decontamination (desorption) studies.

The characteristics of chosen unspiked soil sample were provided in Table- 2 .

\begin{tabular}{|c|c|c|c|}
\hline \multicolumn{4}{|c|}{$\begin{array}{c}\text { TABLE-2 } \\
\text { CHARACTERISTICS OF UNSPIKED SOIL }\end{array}$} \\
\hline $\begin{array}{l}\text { S. } \\
\text { No. }\end{array}$ & Soil properties & Value & Method \\
\hline 1 & $\mathrm{pH}$ & 5 & $\begin{array}{l}\text { USEPA SW-846 } \\
\text { Method 9045D }\end{array}$ \\
\hline 2 & Specific gravity & 1.74 & $\begin{array}{l}\text { ASTM D } 854 \text { - Water } \\
\text { Pycnometer method }\end{array}$ \\
\hline 3 & Bulk density $\left(\mathrm{g} \mathrm{cc}^{-1}\right)$ & 2.2 & $\begin{array}{l}\text { Light compaction } \\
\text { method }\end{array}$ \\
\hline 4 & Coarse sand (\%) & $52.1 \pm 0.5$ & - \\
\hline & Fine sand $(\%)$ & $39.7 \pm 0.6$ & - \\
\hline & Silt (\%) & $5.7 \pm 0.8$ & - \\
\hline & Clay (\%) & $2.6 \pm 0.6$ & - \\
\hline 5 & Carbon $(\%)$ & $2.1 \pm 0.3$ & - \\
\hline 6 & Nitrogen $(\%)$ & $1.4 \pm 0.1$ & - \\
\hline 7 & Permeability $\left(\mathrm{cm} \mathrm{s}^{-1}\right)$ & $2.528 \times 10^{-4}$ & - \\
\hline 8 & Liquid limit (\%) & 62.135 & - \\
\hline 9 & Plastic limit (\%) & 48 & - \\
\hline
\end{tabular}

Preparation of plant based natural surfactant solution: The natural surfactant was extracted from ground material of soap nut pericarp powder by mixing it with water and stirred well for $3 \mathrm{~h}$ at room temperature. The mixer was centrifuged and the supernatant was filtered through series of filters. The resultant filtrate was used as natural surfactant solution. Like this, $10 \%$ stock solution of natural surfactant solution was prepared and dilutions were made from this solution depending on the requirement. The same extraction procedure was adopted for understanding the aqueous solubility enhancement of hexachlorobenzene and naphthalene [20] and for understanding the nature of natural surfactant through the interactions between Congo red and natural surfactant/commercial surfactants [21]. Some properties of $10 \%$ natural surfactant solution were shown in Table-3. The structure of a typical saponin molecule $[26,43]$ is shown in Fig. 1 for getting clarity about sapindus saponin surfactant. Plant based sapindus saponin surfactants were glycosidic compounds containing either a triterpenoid or an alkaloid steroid as a hydrophobic nucleus (aglycone) [44-47]. The nucleus was connected to hydrophilic sugar chains through ether or ester bonds as it was shown in above structure. The simultaneous presences of aglycone and sugar chains provide surface activity.

Aqueous solubility enhancement experiments: All solubility experiments were carried out without soil samples. $25 \mathrm{~mL}$ of different concentrated surfactant solutions were added to the excess of Sudan III $(0.05 \mathrm{~g})$ in $50 \mathrm{~mL}$ screw cap Erlenmeyer flasks. The flasks were equilibrated for about 24 $\mathrm{h}$ by agitating at $180 \mathrm{rpm}$ in a Julabo shaking water bath. The samples were centrifuged and supernatant was taken for 
TABLE-3

SOME PROPERTIES OF NATURAL SURFACTANT [Ref. 20]

\begin{tabular}{|c|c|c|}
\hline Property & Value or description & Ref. \\
\hline Empirical formula & $\left(\mathrm{C}_{26} \mathrm{H}_{31} \mathrm{O}_{10}\right)_{2}$ & \\
\hline Total organic carbon $(\mathrm{TOC})(\mathrm{g} / \mathrm{L})$ & 41 & \\
\hline Chemical oxygen demand (COD) $(\mathrm{g} / \mathrm{L})$ & 124 & \\
\hline Critical micelle concentration (CMC) (\%) & 0.1 & [21] \\
\hline $\mathrm{pH}$ (1\% solution) & 4.5 & \\
\hline Chemical formula & $\mathrm{C}_{41} \mathrm{H}_{61} \mathrm{O}_{18} / \mathrm{C}_{52} \mathrm{H}_{84} \mathrm{O}_{21} \cdot 2 \mathrm{H}_{2} \mathrm{O}$ & {$[41,42]$} \\
\hline Nitrogen and phosphorus for $10 \%$ solution & Not detected & \\
\hline Shape of saponin micelle above CMC & Spherical shape & [23] \\
\hline Hydrodynamic size of micelle (nm) & $10-11.5$ & [23] \\
\hline Size of micelle by voltammetry (nm) & $4.83-5.5$ & [24] \\
\hline Micellar aggregation number by viscosity & $13-21$ & [24] \\
\hline $\mathrm{pK}_{\mathrm{a} 1}$ (negative log of first acidic dissociation constant) & 4.825 & [22] \\
\hline $\mathrm{pK}_{\mathrm{a} 2}$ (negative log of second acidic dissociation constant) & 6.65 & [22] \\
\hline
\end{tabular}

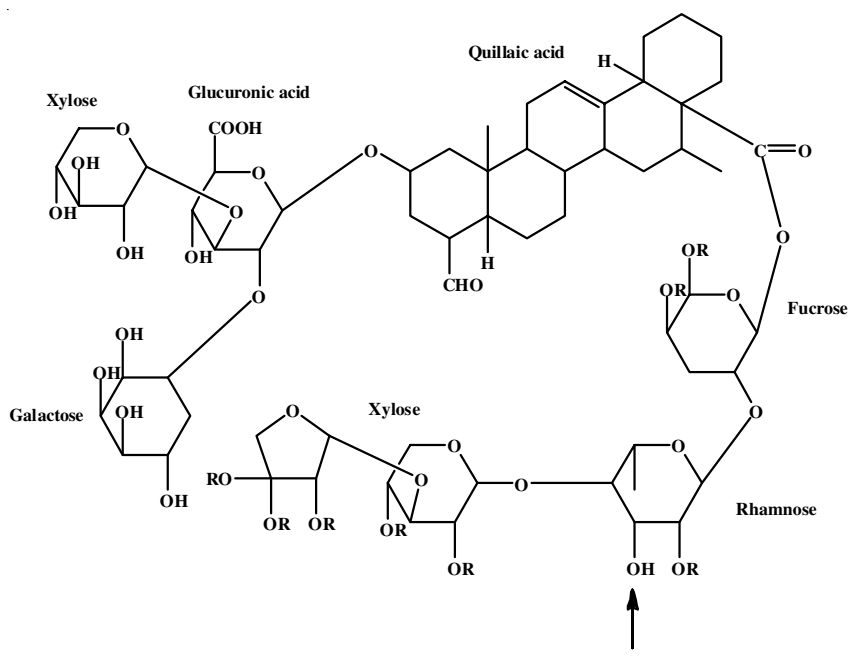

Fig. 1. Structure of saponin molecule

analysis purpose. The samples were spectrophotometrically analyzed at $506 \mathrm{~nm}$ for knowing the solubilized Sudan III. The effect of strong electrolyte, sodium chloride was also studied.

Along with natural surfactant, other surfactants like SDS, CTAB and Triton X-100 were also used for comparison purpose.

Micellar solubilization measurements: The solubilization capacity of Sudan III dye in natural surfactant micelles was evaluated by determining molar solubilization ratio (MSR) or power (SP), which was obtained from Edwards et al. [48]. Molar solubilization ratio was the ratio of moles of solubilized dye to moles of micellized surfactant in solution. Molar solubilization ratio was calculated by using the eqn. 1.

$$
\mathrm{MSR}=\left(\mathrm{S}_{\mathrm{dye}}-\mathrm{S}_{\mathrm{CMC}}\right) /\left(\mathrm{C}_{\text {surf }}-\mathrm{CMC}\right)
$$

where $S_{\text {dye }}$ was the solubilized dye in aqueous soapnut pericarp solution at natural surfactant concentration, $\mathrm{S}_{\mathrm{CMC}}$ was the solubilized dye in aqueous soapnut pericarp solution at CMC, $\mathrm{C}_{\text {surf }}$ was the concentration of natural surfactant in aqueous soapnut pericarp solution and CMC is the critical micellar concentration of natural surfactant. The molar solubilization ratio of natural surfactant micelles was determined from the slope of linear fitting of solubilized dye concentration vs. natural surfactant concentration in solution.

An alternative approach in quantifying the surfactant solubilitization for Sudan III dye was the micelle-water parti- tion coefficient $\left(\mathrm{K}_{\mathrm{m}}\right)$. It represented the effectiveness of solubilization for any surfactant, which was the ratio of the mole fraction of solute in surfactant micelles to the mole fraction of solute in the aqueous phase. The partition coefficient $\left(\mathrm{K}_{\mathrm{m}}\right)$ was calculated using eqn. 2 :

$$
\mathrm{K}_{\mathrm{m}}=\mathrm{X}_{\mathrm{m}} / \mathrm{X}_{\mathrm{a}}
$$

where $X_{m}$ and $X_{a}$ were calculated from eqns. 3 and 4, respectively.

$$
\mathrm{X}_{\mathrm{m}}=\mathrm{MSR} /(1+\mathrm{MSR})
$$

and

$$
\mathrm{X}_{\mathrm{a}}=\mathrm{S}_{\mathrm{CMC}} \times \mathrm{V}_{\mathrm{w}}
$$

where $\mathrm{V}_{\mathrm{w}}$ was the molar volume of water $\left(1.805 \times 10^{-2} \mathrm{~L} \mathrm{~mol}^{-1}\right.$ at $25^{\circ} \mathrm{C}$ ). By putting the $X_{m}$ and $X_{a}$ in eqn. $2, K_{m}$ was rewritten as eqn. 5 as below:

$$
\mathrm{K}_{\mathrm{m}}=\mathrm{MSR} /\left[\mathrm{S}_{\mathrm{CMC}} \times \mathrm{V}_{\mathrm{w}} \times(1+\mathrm{MSR})\right]
$$

The knowledge of partition coefficient was helpful in determining the Gibbs free energy $(\Delta G)$, which helps in the better understanding of the mechanisms associated with the solubilization process. The Gibbs free energy of solubilization was calculated from eqn. 6 .

$$
\Delta \mathrm{G}=-\mathrm{RT} \ln \mathrm{K}_{\mathrm{m}}
$$

where, $\mathrm{R}$ was the gas constant in $\mathrm{J} \mathrm{mol}^{-1} \mathrm{~K}^{-1}\left(8.3145 \mathrm{~J} \mathrm{~mol}^{-1}\right.$ $\mathrm{K}^{-1}$ ) and $\mathrm{T}$ is the temperature in $\mathrm{K}$.

Soil contamination: The soil fraction passing through $600 \mathrm{~mm}$ sieve was spiked with Sudan III to study the performance of natural surfactant solutions in decontamination (desorption).

Sudan III was dissolved in acetone and the soil was added slowly with continuous mixing. Acetone was allowed to evaporate by putting the beaker on hot plate. The dried contaminated soil was transferring into a glass bottle and tumbling for about a week to simulate long-term adsorption found at actual waste sites. This sample was used for desorption studies. Five types of contaminated soils were prepared for desorption studies. Those were $241 \mathrm{mg} / \mathrm{kg}, 98.5541 \mathrm{mg} / \mathrm{kg}, 50.0569 \mathrm{mg} / \mathrm{kg}, 15.501$ $\mathrm{mg} / \mathrm{kg}$ and $5.0462 \mathrm{mg} / \mathrm{kg}$.

Decontamination (desorption)-batch experiments: The contaminated soil (2.5 g) was accurately weighed and added to several $50 \mathrm{~mL}$ Erlenmeyer flasks. $25 \mathrm{~mL}$ of surfactant solution of different concentrations above and below the CMC 
was added to each flask the concentration range of natural surfactant used was $0.05-5 \%(\mathrm{w} / \mathrm{w})$, SDS in the range of 2-12 $\mathrm{mM}, \mathrm{CTAB}$ in the range of $0.5-10 \mathrm{mM}$ and Triton $\mathrm{X}-100$ in the range of $0.2-5 \mathrm{mM}$. The flasks were shaken at room temperature for about $24 \mathrm{~h}$ on a shaker. The samples were withdrawn and centrifuged to separate the soil particles before analyzing for Sudan III.

\section{RESULTS AND DISCUSSION}

Solubility of Sudan III in natural surfactant solutions: The variation of Sudan III solubility in natural surfactant solution in the concentration range of $0.02-20 \%$ by weight was studied and the change of solubility of Sudan III (mM) with $\mathrm{mM}(0.02-2 \%)$ of natural surfactant is shown in Fig. 2. The solubility of Sudan III was increased by increasing the concentration of natural surfactant. The solubility of Sudan III in natural surfactant solution of $2 \%$ concentration was about $8 \mathrm{mg} / \mathrm{L}$. There appears to be a linear relationship between solubility and surfactant concentration up to about $2 \%$ by weight. The solubility of Sudan III in surfactant solutions above $2 \%$ does not linearly increase with concentration but approaches a saturation value. The possible reason for this asymptotic value in solubility could be that the maximum capacity of the micelles for Sudan III or the surfactant was not extracted from the pericarp efficiently at higher surfactant concentration. The surfactant was probably not extracted from pericarp for a $20 \%$ solution as efficiently as for a $10 \%$ solution. Similar type of results were observed for the solubility of hydrochlorobenzene and naphthalene [20,33], polycyclic aromatic hydrocarbons (pyrene, phenanthrene, ace naphthalene and naphthalene) [9] and methylene blue and eosin yellow [23] in the natural surfactant solutions. The solubilization of Sudan III dye was exactly similar to the trend of the solubilization of naphthalene in presence of saponin solution [9].

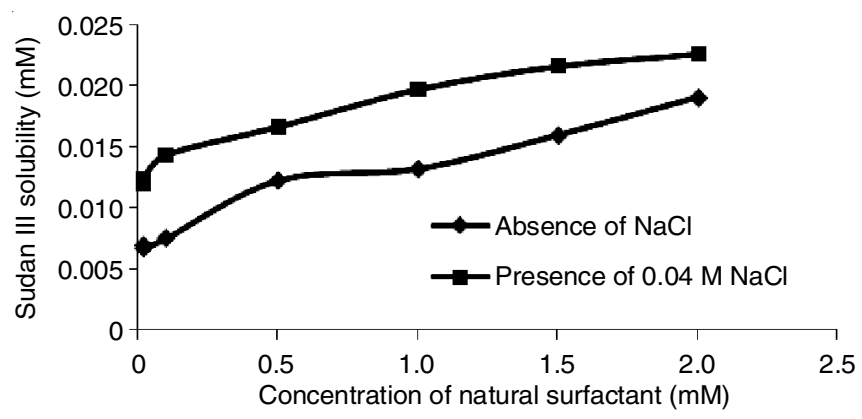

Fig. 2. Variation of Sudan III solubility with natural surfactant

The solubilization of Sudan III was studied in the presence of strong electrolyte, $\mathrm{NaCl}$ also and the effect of electrolyte on the solubility of Sudan III in the natural surfactant is shown in Fig. 2. The solubility of Sudan III was increased in the presence of $\mathrm{NaCl}$. The solubility of Sudan III was linearly changing with the concentration of natural surfactant at low concentrations. At higher concentration of natural surfactant linearity was not maintained between solubility of Sudan III and the concentration of natural surfactant. The reason for increasing the solubility of Sudan III in the presence of $\mathrm{NaCl}$ was that probably the $\mathrm{NaCl}$ changes the micelle size as well as micelle shape. Secondly, the natural surfactant molecules may be available at the interface of micelles. They may be present in the bulk of the solution. Increase the concentration of natural surfactant may lead to the formation of rod like micelles. Sometimes, probably the equilibrium may establish between spherical and rod like micelles at higher concentration of natural surfactant.

The solubility of Sudan III dye was increased approximately $2 \mathrm{mM}$ in presence of $0.04 \mathrm{M} \mathrm{NaCl}$ at all concentrations of natural surfactant. This was similar to the solubility of methylene blue and eosin yellow [23] and phenanthrene [9] in presence of $\mathrm{NaCl}$, with saponin micelles and their solubilities were appreciably increased in presence of $\mathrm{NaCl}$ due to screening of electrostatic interaction of the head groups in presence of ionic salt [43] and reaching dyes molecules to accommodate in a micelle.

The molar solublization ratio (MSR) value obtained from the slope of solubilization curve (Fig. 2), which is plotted between the natural surfactant concentration in $\mathrm{mM}$ and Sudan III dye concentration in $\mathrm{mM}$. In a similar lines, the weight solubilization ratio (WSR) was also obtained from the slope of the plot made between surfactant concentration in mass unit $(\mathrm{mg} / \mathrm{L})$ and Sudan III concentration in mass units $(\mathrm{mg} / \mathrm{L})$. The molar solubilization ratio and weight solubilization ratio values of natural surfactant for Sudan III were obtained from the solubilization curves in Fig. 2 (solubilization curve in mass units was not shown) and these values were arranged in Tables 4 and 5. The molar solubilization ratio value was following the same trend observed in the solubilization of hexachlorobenzene in presence of natural surfactant [33].

The micelle-water partition coefficient $\left(\mathrm{K}_{\mathrm{m}}\right)$, which represents the partitioning of solute between surfactant micelles and the aqueous phase was calculated by using eqn. 5 by using solubilization data and the values were shown in Tables 4 and 5. The $\mathrm{K}_{\mathrm{m}}$ was also supported solubilization of Sudan III dye in natural surfactant solution.

The knowledge of thermodynamic parameter such as a change in Gibb's free energy $(\Delta G)$ was important for understanding the feasibility of solubilization process. The Gibb's free energy of solubilization $(\Delta \mathrm{G})$ was calculated for Sudan III dye by using eqn. 6 and the values were found to be -24.58

TABLE-4

SOLUBILIZATION PARAMETERS OF NS/TRITON X-100/SDS/CTAB FOR SUDAN III IN ABSENCE OF $0.04 \mathrm{M} \mathrm{NaCl}$ AND GIBBS FREE ENERGY OF SOLUBILIZATION $(\Delta \mathrm{G})$ AT $27^{\circ} \mathrm{C}$

\begin{tabular}{cccccccc}
\hline Surfactant & MSR & $\mathrm{R}^{2}$ & WSR & $\mathrm{R}^{2}$ & $\mathrm{~K}_{\mathrm{m}}$ & $\log \mathrm{K}_{\mathrm{m}}$ & $\left.\Delta \mathrm{G}_{(\mathrm{kJ} \mathrm{mol}} \mathrm{K}^{-1}\right)$ \\
\hline Natural surfactant & 0.006 & 0.937 & 0.002 & 0.937 & 19061.3632 & 4.2810 & -24.58 \\
Triton X-100 & 0.005 & 0.979 & 0.002 & 0.979 & 69558.4010 & 4.8423 & -27.81 \\
SDS & 0.001 & 0.946 & 0.001 & 0.987 & 9349.9770 & 3.9708 & -22.81 \\
CTAB & 0.005 & 0.987 & 0.004 & 0.997 & 34194.7385 & 4.5340 & -26.04 \\
\hline
\end{tabular}


TABLE-5

SOLUBILIZATION PARAMETERS OF NS/TRITON X-100/SDS/CTAB FOR SUDAN III IN PRESENCE OF NaCl AND GIBBS FREE ENERGY OF SOLUBILIZATION $(\Delta \mathrm{G})$ AT $27^{\circ} \mathrm{C}$

\begin{tabular}{cccccccc}
\hline Surfactant & MSR & $\mathrm{R}^{2}$ & WSR & $\mathrm{R}^{2}$ & $\mathrm{~K}_{\mathrm{m}}$ & $\log \mathrm{K}_{\mathrm{m}}$ & $\Delta \mathrm{G}\left(\mathrm{kJ} \mathrm{mol}{ }^{-1} \mathrm{~K}^{-1}\right)$ \\
\hline Natural surfactant & 0.005 & 0.941 & 0.001 & 0.941 & 44045.1247 & 4.6439 & -26.67 \\
Triton X-100 & 0.005 & 0.974 & 0.002 & 0.974 & 76287.6695 & 4.8825 & -28.04 \\
SDS & 0.001 & 0.993 & 0.001 & 0.991 & 4153.9800 & 3.6185 & -20.78 \\
CTAB & 0.007 & 0.999 & 0.007 & 0.999 & 19666.3148 & 4.2937 & -24.66 \\
\hline
\end{tabular}

$\mathrm{kJ} \mathrm{mol}^{-1} \mathrm{~K}^{-1}$ and $-26.67 \mathrm{~kJ} \mathrm{~mol}^{-1} \mathrm{~K}^{-1}$ in absence of $\mathrm{NaCl}$ and in presence of $0.04 \mathrm{M} \mathrm{NaCl}$, respectively. These values were also arranged in Tables 4 and 5. These values support the feasibility of solubilization of Sudan III in natural surfactant.

Solubility of Sudan III in SDS, CTAB and Triton X-100 surfactant solutions: Solubility of Sudan III in SDS solutions of several concentrations below and above CMC was studied. There was a linear relationship between SDS concentration and solubility at low concentrations of surfactant. Maximum solubility was obtained with a $20 \mathrm{mM}$ SDS solution. The value was $7 \mathrm{mg} / \mathrm{L}$. In presence of $0.04 \%$ of $\mathrm{NaCl}$, the solubility values were decreased which was opposite to the natural surfactant.

Similar to the SDS, solubility of Sudan III in CTAB solutions of several concentrations below and above CMC was studied. In this case also linearity observed between solubility and CTAB concentrations at low concentrations of the surfactant. Maximum solubility was obtained with a $10 \mathrm{mM} \mathrm{CTAB}$ solution. That value was foun to be $20 \mathrm{mg} / \mathrm{L}$. In the presence of $\mathrm{NaCl}$ the solubility was decreased in case of CTAB also like SDS case.

The solubility of Sudan III dye in presence of $0.04 \mathrm{M}$ $\mathrm{NaCl}$ was decreased in case of ionic surfactants such as SDS and CTAB but it increased in natural surfactant solutions. Similar behaviour was observed in case of methylene blue and eosin yellow dyes [23] and phenanthrene [9] in presence of saponin surfactant. This was mainly due to reduction of the electrostatic repulsions between the head groups of saponin molecules by partially screening the negative charge of the surfactant head groups in presence of $\mathrm{NaCl}$.

Similar to all surfactants, solubility of Sudan III in Triton $\mathrm{X}-100$ solutions of several concentrations below and above CMC was also studied. At low concentrations of Triton X-100, the solubility was linear with the concentration of surfactant. Maximum solubility was obtained with $15 \mathrm{mM}$ Triton X-100 solution. Its value was $31 \mathrm{mg} / \mathrm{L}$. In presence of $\mathrm{NaCl}$ the solubility was increased in case of Triton X-100. In case of ionic surfactants like SDS and CTAB, the solubility of Sudan III in presence of $\mathrm{NaCl}$ was decreased. But in case of Triton X-100, the solubility of Sudan III in the presence of $\mathrm{NaCl}$ was increased. Similar to Triton X-100, the natural surfactant was also behaved because in presence of $\mathrm{NaCl}$ the solubility of Sudan III was increased.

Therefore, it was clear that the natural surfactant was not an ionic surfactant and this conclusion already made by Somasekhara Reddy et al. [21]. It was similar to non-ionic surfactant. But it was too early to conclude like this. Some more experiments may be performed to make a final conclusion. Variation of solubility of Sudan III along with concentration of various surfactants like SDS, CTAB and Triton X-100 is shown in Fig. 3 and the effect of $\mathrm{NaCl}$ on variation of solubi-



Fig. 3. Solubilization of Sudan III in presence of SDS, CTAB and Triton $\mathrm{X}-100$

lity in presence of different surfactants was also shown in the same figure.

$\mathrm{K}_{\mathrm{m}}$ and $\Delta \mathrm{G}$ values for all other synthetic surfactants (SDS, CTAB and Triton X-100) were also calculated similar to the natural surfactant and the values were given in Tables 4 and 5 .

From Figs. 2 and 3 and Tables 4 and 5, the solubilizing capacity of surfactants for solubility of Sudan III dye in absence of $\mathrm{NaCl}$ is written as:

\section{Triton X-100 $>$ CTAB $>$ NS $>$ SDS}

Batch desorption studies: Desorption studies were used to evaluate the efficiency of natural surfactant solutions to desorp Sudan III from soil. SDS, CTAB and Triton X-100 were also employed in desorption studies to compare the performance of natural surfactant solutions. The amount of Sudan III desorbed from soil and solubilized by natural surfactant and other surfactants were estimated as a percentage of Sudan III initially present in the soil and were reported as per cent recoveries.

Desorption studies with natural surfactant solutions: Desorption studies were used to evaluate the efficiency of natural surfactant solutions to desorb Sudan III dye from soil. The desorption of Sudan III from the soils of different contaminations was studied. The soil contaminations were $241 \mathrm{mg} / \mathrm{kg}$, $98.5541 \mathrm{mg} / \mathrm{kg}, 50.9569 \mathrm{mg} / \mathrm{kg}, 15.501 \mathrm{mg} / \mathrm{kg}$ and 5.4062 $\mathrm{mg} / \mathrm{kg}$. Repeating washing process may clean the soil to a desired level. Desorption of Sudan III from contaminated soil with natural surfactant is shown in Figs. 4 and 5 which show the percent Sudan III dye desorbed from soil by natural surfactant solutions for different contamination levels.

From Fig. 5, the recovery of Sudan III dye at high contamination level $(241 \mathrm{mg} / \mathrm{kg})$ was linear with the concentration of natural surfactant. 




Fig. 4. Desorption of Sudan III from soil with natural surfactant solutions



Fig. 5. Variation (\%) desorption of Sudan III from soil with natural surfactant solutions

The desorption percentage of Sudan III from the contaminated soils were $94,61,76$ and $83 \%$ for contaminated soils of $241 \mathrm{mg} / \mathrm{L}, 98.5541,50.0569 \mathrm{mg} / \mathrm{L}$ and $15.501 \mathrm{mg} / \mathrm{L}$, respectively within the experimental error.

The desorption data is plotted in Fig. 6 as a Freundlich desorption isotherm with Sudan III remaining on the soil per gram of soil $\left(\mathrm{Q}_{\mathrm{e}}\right)$ versus the aqueous phase Sudan III concentration $\left(\mathrm{C}_{\mathrm{e}}\right)$. It was observed that the linear relationship between

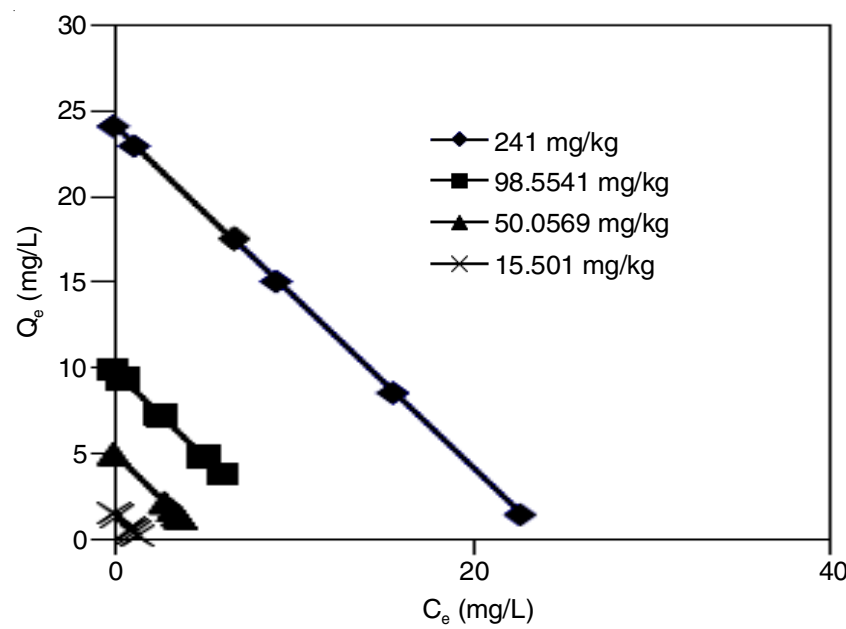

Fig. 6. Freundlich desorption isotherm for Sudan III with natural surfactant the Sudan III on the soil and the aqueous phase $\left(\mathrm{C}_{\mathrm{e}}\right)$ concentration for all soil contaminations. Kommalapati et al. [33] not observed linear relationship between the hexachlorobenzene on the soil and the aqueous phase concentration at lower contaminated soils. This linearity particularly failed at high surfactant concentrations. At low contaminated levels very little Sudan III was available for desorption. This was indicated by the decrease in the value of $\mathrm{Q}_{\mathrm{e}}$ or Sudan III remaining on soil for a relative narrow range of aqueous phase Sudan III concentration.

A Langmuir isotherm was also plotted in Fig. 7, for desorption data. The data fit the Langmuir isotherm at higher concentration. It was observed that the isotherm was not linear at lower contamination level. The linearity failed particularly at high surfactant concentration.

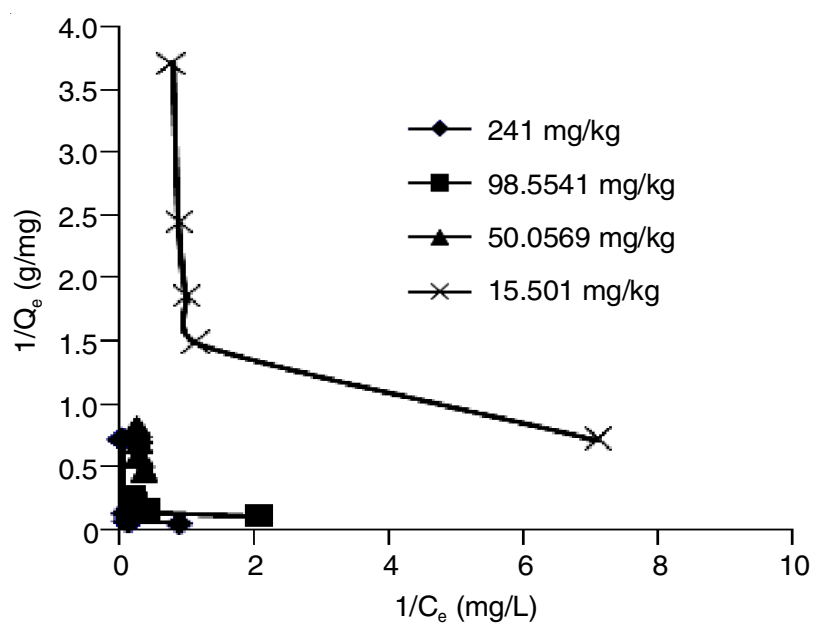

Fig. 7. Langmuir desorption isotherm for Sudan III in case of natural surfactant

Desorption studies with Triton $\mathrm{X}$-100 solutions: In case of Triton X-100 also, plot is made between equilibrium aqueous phase Sudan III concentration that was desorbed from the soil and concentration of Triton X-100 for different levels of contaminations. For Triton X-100, the same trend as followed for natural surfactant solution was observed (Fig. 8). For low contamination levels, aqueous phase Sudan III was significantly less than the Sudan III solubility in the respective solutions. For the higher contamination level there was a sharp increase in the aqueous phase concentration of Sudan III. The sharp increase was also noticed in solubility studies also (Fig. 9).

The Freundlich and the Langmuir desorption isotherms for Sudan III dye are plotted in Figs. 10 and 11, respectively for the desorption of Sudan III dye from the different contaminated levels. The Freundlich desorption isotherm was not fit for low contaminated soil as the linearity was not observed in this case. But in case of Langmuir isotherm, they fit for all contaminated levels as the linearity was observed at all contaminated levels.

Desorption studies with CTAB solutions: In contrast to our expectations the CTAB was not desorbed Sudan III dye from the contaminated soils up to $10 \mathrm{mM}$. The reasons may be (i) Probably the presence of soil significantly alters the CMC of CTAB and (ii) Due to electrostatic attraction between positive CTAB surfactant ions and negative soil, the added 




Fig. 8. Desorption of Sudan III from soil with Triton X-100

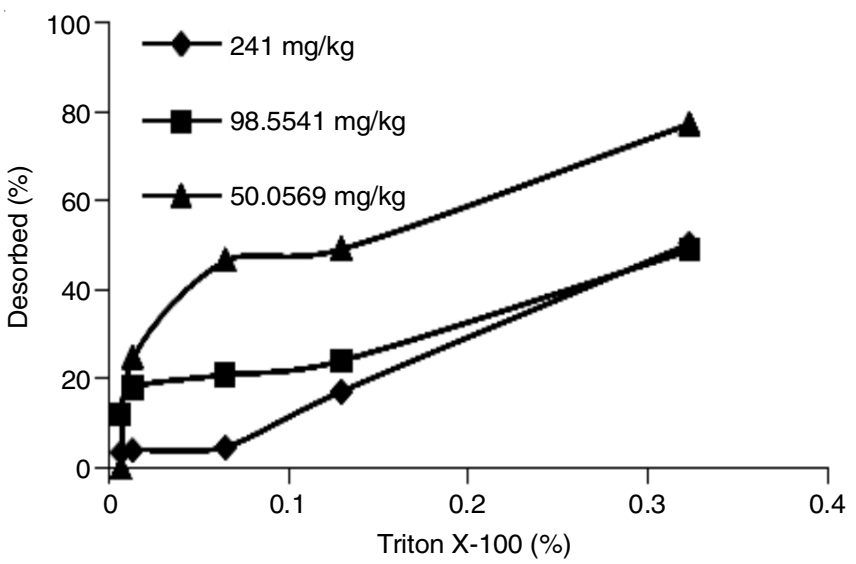

Fig. 9. Variation $\%$ desorption of Sudan III from soil with Triton X-100



Fig. 10. Freundlich desorption isotherm for Sudan III in case of Triton X100

CTAB surfactant ions were adsorbed over the soil. The CMC of CTAB in soil-water system may be higher than $1 \mathrm{mM}$ because of above reasons. Therefore, by increase the concentration of $\mathrm{CTAB}$ beyond $10 \mathrm{mM}$ may be useful for extraction or recovery of Sudan III from contaminated soil.

Desorption studies with SDS solutions: In presence of SDS also shows the similar trend of natural surfactant and Triton X-100. The desorption capacity of SDS was less than that of the natural surfactant and Triton X-100. The desorption graphs and desorption isotherms (the Freundlich and the



Fig. 11. Langmuir desorption isotherm for Sudan III in case of Triton X-100

Langmuir) were also drawn (figures are not shown) for understanding the desorption of Sudan III dye from different contaminated soil levels and the results were compared that of natural surfactant and other synthetic surfactant.

Comparison between natural surfactant and commercial surfactants: All chosen synthetic surfactants (Triton X100, CTAB and SDS) and plant based natural surfactant have shown similar behaviour in desorbing Sudan III dye from contaminated soil. The surfactants such as Triton X-100, natural surfactant and SDS were capable to desorb Sudan III dye from high contaminated soil very effectively. Triton X-100 was not capable to desorb the dye from low contaminated soil. The desorption capability in desorption of Sudan III dye from contaminated soils was comparable with synthetic surfactants and the removing capacity of surfactants may be written in increasing order as

$$
\text { Triton X-100 }>\text { NS }>\text { SDS }>\text { CTAB }
$$

These investigations reveal that the plant based natural surfactant solutions were comparable in performance to synthetic surfactants in solubilizing and desorbing hydrophobic compounds like Sudan III dye and should be further investigated.

\section{Conclusion}

The present investigations reveal that the natural surfactant was excellently used for treatment of contaminated soils particularly contaminated with hydrophobic organic compounds like Sudan III dye. The natural surfactant is a plant based biodegradable, eco-friendly, renewable, non-toxic, high foaming capacity, low-cost abundantly available surfactant. Recently the cost analysis about this surfactant was performed and concluded that it is a low-cost surfactant in terms of the amount of surfactant required to form the micelles [49]. Therefore, it can be used for the treatment purpose economically.

It is noted that by using natural surfactant, revenue will be created to the farmers because the Sapindus mukorossi and other similar trees or shrubs like Sapindus emerginatus and Sapindus tripoliatus, which were producing natural surfactants may be grown without much water. Very little water was required only at the beginning.

Natural surfactant solutions were used to enhance aqueous solubility of Sudan III and to de-sorb Sudan III from contaminated soil. Solubility of Sudan III increases linearly with surfactant concentration beyond CMC. However, the solubility 
beyond $10 \%$ natural surfactant that concentration was not linear and follows a saturation-type curve. The inefficient extraction of surfactant into water and saturation of the surfactant micelles with Sudan III were thought to be responsible. The desorption isotherms follow both Frendlich and Langmuir isotherms at higher soil contamination levels. Sudan III dye concentration in the natural surfactant solution approached up to $90 \%$ of the Sudan III dye solubility in the respective solutions in batch desorption studies for soils contaminated to high levels and the Sudan III recoveries from soils contaminated to lower levels. Solubility of Sudan III dye in Triton X-100 solutions increase linearly with Triton X-100 concentrations beyond CMC for contamination. Similar behaviour was also observed with other surfactants. Natural surfactant solutions were comparable to commercial surfactants solutions in solubilizing Sudan III. Batch desorption studies show the natural surfactant solutions were favourable for desorbing Sudan III dye from soil like other surfactants. From this investigations, it was concluded that the desorption capacity of chosen surfactants may be written in increasing order as:

$$
\text { Triton } \mathrm{X}-100>\mathrm{NS}>\mathrm{SDS}>\mathrm{CTAB}
$$

The natural surfactant behaves like a Triton X-100. The reasons were shown below:

- The spectrum of Sudan III with natural surfactant and with other two non-ionic surfactants like Triton X-100 and Tween- 80 was the same because the new peak was formed for all the surfactants at $510 \mathrm{~nm}$ only. Probably, this may be due to the formation of similar product between the surfactants and congo red [21].

- The aqueous solubility enhancement of Sudan III dye in presence of surfactants such as Triton X-100, NS, SDS and $\mathrm{CTAB}$ was increasing in the following order in absence of $\mathrm{NaCl}$.

$$
\text { Triton X-100 }>\text { CTAB }>\text { NS }>\text { SDS }
$$

The solubility of Sudan III in presence of $0.04 \mathrm{M}$ of $\mathrm{NaCl}$ was increased in case of non-ionic surfactants like NS and Triton X-100 and in case of ionic surfactants such as SDS and CTAB; the solubility of Sudan III dye was decreased.

- The desorption behaviour of natural surfactant was also similar to the behaviour of Triton X-100.

\section{ACKNOWLEDGEMENTS}

The authors are grateful to the AICTE (All India Council for Technical Education, New Delhi) for the financial assistance to establish the infrastructure required to carry out the present research work. The authors are also grateful to The Management, The Director and The Principal of G.P.R. Engineering College (Autonomous), Kurnool, India for their constant encouragement and help.

\section{CONFLICT OF INTEREST}

The authors declare that there is no conflict of interests regarding the publication of this article.

\section{REFERENCES}

1. H.L. Huang and W.M.G. Lee, J. Environ. Eng., 128, 60 (2002); https://doi.org/10.1061/(ASCE)0733-9372(2002)128:1(60).

2. S. Paria, Adv. Colloid Interface Sci., 138, 24 (2008); https://doi.org/10.1016/j.cis.2007.11.001.

3. R.G. Luthy, D.A. Dzombak, C.A. Peters, S.B. Roy, A. Ramaswami, D.V. Nakles and B.R. Nott, Environ. Sci. Technol., 28, 266A (1994); https://doi.org/10.1021/es00055a002.

4. D.M. Mackay and J.A. Cherry, Environ. Sci. Technol., 23, 630 (1989); https://doi.org/10.1021/es00064a001.

5. W.D. Elis, J.R. Payne and G.D. McNaab, Treatment of Contaminated Soils with Aqueous Surfactants, EPA/600/2-85/129, U.S. Environmental Protection Agency, Cincinnati, OH, p. 129 (1985).

6. C. Trellu, E. Mousset, Y. Pechaud, D. Huguenot, E.D. van Hullebusch, G. Esposito and M.A. Oturan, J. Hazard. Mater., 306, 149 (2016); https://doi.org/10.1016/j.jhazmat.2015.12.008.

7. M. Davin, A. Starren, M. Deleu, G. Lognay, G. Colinet and M.-L. Fauconnier, Chemosphere, 194, 414 (2018); https://doi.org/10.1016/j.chemosphere.2017.11.174.

8. S. Gan, E.V. Lau and H.K. Ng, J. Hazard. Mater, 172, 532 (2009); https://doi.org/10.1016/j.jhazmat.2009.07.118.

9. W. Zhou, X. Wang, C. Chen and L. Zhu, Colloid Surf. A, 425, 122 (2013); https://doi.org/10.1016/j.colsurfa.2013.02.055.

10. X. Mao, R. Jiang, W. Xiao and J. Yu, J. Hazard. Mater, 285, 419 (2015); https://doi.org/10.1016/j.jhazmat.2014.12.009.

11. A.S. Abdul and T.L. Gibson, Environ. Sci. Technol., 25, 665 (1991); https://doi.org/10.1021/es00016a009.

12. K.H. Dma and N.C. Ann, J. Sci. Technol., 28, 2319 (1993).

13. C.T. Jafvert and H.P.L. Hoof, Water Res., 28, 1009 (1994); https://doi.org/10.1016/0043-1354(94)90185-6.

14. Z. Liu, D.A. Edwards and R.G. Luthy, Water Res., 26, 1337 (1992); https://doi.org/10.1016/0043-1354(92)90128-Q.

15. V. Reddy, R.S. Torati, S. Oh and C.G. Kim, Ind. Eng. Chem. Res., 52, 556 (2013); https://doi.org/10.1021/ie302037c.

16. A. Samanta, K. Ojha, A. Madal and A. Sarkar, J. Pet. Eng. Technol., 3, 20 (2013).

17. B. Ankamwar, M. Chaudhary and M. Sastry, Inorg. Met.-Org. NanoMet. Chem., 35, 19 (2005); https://doi.org/10.1081/SIM-200047527.

18. J. Huang, Q. Li, D. Sun, Y. Lu, Y. Su, X. Yang, H. Wang, Y. Wang, W. Shao and N. He, Nanotechnology, 18, 105104 (2007); https://doi.org/10.1088/0957-4484/18/10/105104.

19. B.Z. Awen, S. Ganapati and B.R. Chandu, Res. J. Pharm. Biol.Chem. Sci., 1, 35 (2010).

20. D. Roy, R.R. Kommalapati, S.S. Mandava, K.T. Valsaraj and W.D. Constant, Environ. Sci. Technol., 31, 670 (1997); https://doi.org/10.1021/es960181y.

21. M.C. Somasekhara Reddy, S.M. Sarvar Jahan, K. Sridevi, and G.V. Subba Reddy, Asian J. Chem., (Communicated).

22. S.-T. Muntaha and M.N. Khan, J. Clean. Prod., 93, 145 (2015); https://doi.org/10.1016/j.jclepro.2015.01.023.

23. K. Samal, C. Das and K. Mohanty, Dyes Pigments, 140, 100 (2017); https://doi.org/10.1016/j.dyepig.2017.01.031.

24. S. Balakrishnan, S. Varughese and A.P. Deshpande, Tenside Surf. Deter. 43, 262 (2006); https://doi.org/10.3139/113.100315.

25. M.N. Kumar, B. Govindh and N. Annapurna, Asian J. Chem., 29, 2541 (2017); https://doi.org/10.14233/ajchem.2017.20842A

26. A. Pradhan and A. Bhattacharyya, J. Clean. Prod., 150, 127 (2017); https://doi.org/10.1016/j.jclepro.2017.03.013.

27. C. Schmitt, B. Grassl, G. Lespes, J. Desbrieres, V. Pellerin, S. Reynaud, J. Gigault and V.A. Hackley, Biomacromolecules, 15, 856 (2014); https://doi.org/10.1021/bm401708m.

28. A.B. Chhetri, K.C. Watts, M.S. Rahman and M.R. Islam, Energy Soucres A, 31, 1893 (2009); https://doi.org/10.1080/15567030802462622.

29. K.J. Rao and S. Paria, J. Phys. Chem. B, 113, 474 (2009); https://doi.org/10.1021/jp8071298.

30. J. Singh, S. Sinha, N. Batra and A. Joshi, Environ. Technol., 33, 349 (2012); https://doi.org/10.1080/09593330.2011.572925. 
31. M.B. Sarma, S.B. Gogoi, D. Devi and B. Goswami, J. Sci. Ind. Res., 71, 270 (2012).

32. S. Khandelwal and Y.R. Chauhan, J. Chem. Pharm. Res., 4, 4219 (2012).

33. R.R. Kommalapati, K.T. Valsaraj, W.D. Constant and D. Roy, Water Res., 31, 2161 (1997); https://doi.org/10.1016/S0043-1354(97)00052-3.

34. R.R. Kommalapati, K.T. Valsaraj, W.D. Constant and D. Roy, J. Hazard. Mater, 60, 73 (1998); https://doi.org/10.1016/S0304-3894(97)00156-8.

35. S. Mukherjee, S. Mukhopadhyay, A. Pariatamby, G. Redzwan, M.A. Hashim and B.S. Gupta, J. Taiwan Inst. Chem. Eng., 53, 15 (2015); https://doi.org/10.1016/j.jtice.2015.02.037.

36. S. Song, L. Zhu and W. Zhou, Environ. Pollut., 156, 1368 (2008); https://doi.org/10.1016/j.envpol.2008.06.018.

37. Z.M. Gusiatin and E. Klimiuk, Chemosphere, 86, 383 (2012); https://doi.org/10.1016/j.chemosphere.2011.10.027.

38. S. Mukhopadhyay, S. Mukherjee, M.A. Hashim and B. Sen Gupta, Chemosphere, 119, 355 (2015); https://doi.org/10.1016/j.chemosphere.2014.06.087.

39. K.-J. Hong, S. Tokunaga and T. Kajiuchi, Chemosphere, 49, 379 (2002); https://doi.org/10.1016/S0045-6535(02)00321-1.
40. M. Cao, Y. Hu, Q. Sun, L. Wang, J. Chen and X. Lu, Environ. Pollut., 174, 93 (2013); https://doi.org/10.1016/j.envpol.2012.11.015.

41. M. Zhang, H. Gao and P. Liu, Chinese Patent, CN 89-103634 (1989).

42. L.R. Row and C. Rukmini, Indian J. Chem., 4, 36 (1966).

43. S. Mitra and S.R. Dungan, J. Agric. Food Chem., 45, 1587 (1997); https://doi.org/10.1021/jf960349z.

44. R. Ghagi, S.K. Satpute, B.A. Chopade and A.G. Banpurkar, Ind. J. Sci. Technol., 4, 530 (2011).

45. C.H. Yang, Y.C. Huang, Y.F. Chen and M.H. Chang, J. Food Drug Anal., 18, 155 (2008).

46. W. Oleszek and Z. Bialy, J. Chromatogr. A, 1112, 78 (2006); https://doi.org/10.1016/j.chroma.2006.01.037.

47. E. Karimi, H.Z.E. Jaafar and S. Ahmad, Molecules, 16, 4438 (2011); https://doi.org/10.3390/molecules16064438.

48. D.A. Edwards, R.G. Luthy and Z. Liu, Sci. Tech. (Paris), 25, 127 (1991); https://doi.org/10.1021/es00013a014.

49. A. Basu, S. Basu, S. Bandyopadhyay and R. Chowdhury, Ind. Crops Prod., 77, 920 (2015); https://doi.org/10.1016/j.indcrop.2015.10.006. 